\title{
Expansão da pré-escola em instituições com oferta de ensino fundamental: reafirmando o direito das crianças à qualidade
}

\begin{abstract}
Resumo: O texto tem como objetivo discutir questões implicadas no direito à educação infantil de qualidade, fragilizado no contexto da universalização da matrícula escolar da pré-escola. Dentre os diferentes arranjos realizados nos sistemas de ensino, a oferta de turmas em escolas antes exclusivamente de ensino fundamental pode por em risco a especificidade da educação infantil, mas, por outro lado, poderá contribuir para uma articulação entre estas duas etapas da educação básica, trazendo continuidade aos processos vivenciados pelas crianças. Nosso argumento é no sentido de que o país já dispõe de ordenamento jurídico, orientações oficiais e aportes teóricos suficientes para subsidiar uma expansão da cobertura para a faixa etária de quatro e cinco anos dentro de critérios de qualidade que respeitem o direito a bem viver os tempos de infância para todas as crianças no início da vida escolar.
\end{abstract}

Palavras-chave: Educação Infantil. Pré-escola. Qualidade. Ensino Fundamental. Universalização.

\section{Expansion of preschool classes in elementary schools: reaffirming the right of children to quality}

Abstract: The study intends to discuss issues implied in the right to quality early childhood education weakened in the context of preschool enrollment universalization. Among the different arrangements made in the education systems, the addition of preschool education classes in schools that were previously exclusively elementary schools could put the specificity of early childhood education in jeopardy, but it could also contribute to an articulation between these two stages of basic education, bringing continuity to the process experienced by the children. Our argument is in the sense that the country has sufficient legal order, official orientations and theoretical contributions to subsidize coverage expansion to ages four and five-years-old within the quality criteria that respect all children's right to live well their childhood years at the beginning of school life.

Keywords: Early Childhood Education. Preschool. Quality. Elementary Education. Universalization.

\footnotetext{
1 Doutora em Educação pela Universidade Federal do Rio Grande do Sul. Professora Adjunta da Área de Política e Gestão da Educação da Faculdade de Educação da UFRGS. Integrante do Núcleo de Política e Gestão da Educação. E-mail: malurflores@gmail.com

2 Mestre em Educação pela Universidade Federal do Rio Grande do Sul (UFRGS). Professora da Rede Municipal de Educação de Novo Hamburgo/RS. Integrante de Grupo de Pesquisa sobre Políticas Públicas de Educação Infantil na Faculdade de Educação da UFRGS. E-mail: arietebr50@gmail.com

${ }^{3}$ Especialista em Docência na Educação Infantil pela Universidade Federal do Rio Grande do Sul (UFRGS). Professora da Rede Municipal de Educação de Novo Hamburgo/RS. Integrante de Grupo de Pesquisa sobre Políticas Públicas de Educação Infantil na Faculdade de Educação da UFRGS. E-mail: clauderiasantos@gmail.com
} 


\section{Contextualizando o tema que trazemos ao debate}

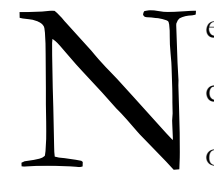

este artigo, daremos visibilidade a questões referentes ao direito à educação de qualidade, colocando no centro do debate a expansão da matrícula pré-escolar em instituições com oferta de ensino fundamental. Nosso objetivo é evidenciar a necessidade de um adequado processo de acolhimento às crianças no início de sua vida escolar, por ser este um direito, bem como um imperativo do ponto de vista das normas educacionais. Defendemos que este encontro entre as duas primeiras etapas da educação básica em uma mesma instituição possa ser explorado em sua potência, a partir da promoção de experiências de aprendizagem efetivas e prazerosas para as crianças entre quatro e seis anos, repercutindo em trajetórias escolares mais bem sucedidas e felizes.

Do ponto de vista legal, de acordo com a Lei de Diretrizes e Bases da Educação Nacional N ${ }^{\circ}$ 9394/96 (Ldben), a Educação Infantil é a primeira etapa da Educação Básica e “[...] tem como finalidade o desenvolvimento integral da criança de zero a cinco anos de idade em seus aspectos físico, afetivo, intelectual, linguístico e social, complementando a ação da família e da comunidade." (BRASIL, Lei no 9.394/96, art. 29). Assim, podemos afirmar que as creches e pré-escolas "[...] possuem um caráter institucional e educacional diverso daquele dos contextos domésticos, dos ditos programas alternativos à educação de crianças de zero a cinco anos de idade, ou da educação não formal”. (BRASIL, 2009b, Parecer CNE/CEB No. 20, p.4).

Nesta perspectiva, colocado o imperativo de universalização da matrícula para crianças de quatro e cinco anos em turmas de pré-escola, cujo prazo legal indicado na Emenda Constitucional 59/09 foi o ano letivo de 2016 (BRASIL, EC 59/09, Art. 6ºs , os municípios, prioritariamente responsáveis por esta oferta de acordo com a Constituição Federal de 1988 (BRASIL, CF/88, Art. 211, Parágrafo 2º tiveram a incumbência de, progressivamente, efetivar a necessária ampliação da cobertura de atendimento nos respectivos sistemas de ensino. Como em certos estados do país vem ocorrendo uma diminuição do número de matrículas no ensino fundamental, em consequência da redução da natalidade, tem sido possível a alguns municípios a abertura de novas turmas em escolas da rede própria que até então eram destinadas exclusivamente ao ensino fundamental. Como a colaboração entre os entes federados para a universalização do ensino obrigatório encontra-se determinada na CF/88 (BRASIL, CF/88, Art. 211, Parágrafo $4^{\circ}$ ), alguns municípios estão expandindo a oferta, também, em colaboração com as redes estaduais, que cedem salas ociosas para alocação de turmas de pré-escola, cuja responsabilidade de mantença é municipal.

A partir de nosso convívio com gestores/as, docentes e até familiares, nestes casos em que as novas turmas de pré-escola são abertas em instituições que não atendem exclusivamente educação infantil, tem sido comum ouvirmos a afirmação de que, agora, "as crianças de quatro e cinco anos foram para o 
ensino fundamental". Contudo, queremos demarcar com este texto que tal afirmação é um equívoco que pode ter consequências danosas, apesar de parecer uma simples e ingênua declaração, pois ainda que as crianças sejam matriculadas em turmas com funcionamento em salas localizadas em escolas que oferecem ensino fundamental e/ou ensino médio, estas crianças possuem quatro ou cinco anos e tem direito a uma vaga na pré-escola; isto é, fazem parte do grupo de crianças matriculadas na educaşão infantil.

Sendo assim, o que de fato ocorre é que uma escola que se enquadre nesta situação deixa de oferecer exclusivamente a etapa subsequente à educação infantil e precisa comprometer-se com a nova oferta, atendendo a tudo aquilo que determinam as leis e os documentos normativos e orientadores para a primeira etapa da educação básica, considerando-se, em especial, as atuais Diretrizes Curriculares Nacionais para a Educação Infantil, documento que fixa as normas para atendimento a esta etapa, aprofundando conceitualmente pressupostos fundamentais e indicando elementos organizadores das práticas cotidianas em espaços de educação coletiva de crianças de até cinco anos (BRASIL, 2009a, CNE/CEB, Resolução 05/09).

A partir de tal entendimento, estes espaços educacionais devem apresentar as condições de oferta vigentes no âmbito de seus sistemas, em consonância com os documentos nacionais, sendo esta responsabilidade compartilhada entre as secretarias de educação, mantenedoras das instituições e o respectivo conselho de educação, instância com papel normatizador, de supervisão e de fiscalização das instituições educacionais. Afirmamos, ainda, a importância dos documentos orientadores do Ministério da Educação (MEC, 2006a; 2006b; 2009c; 2012; 2015), que tratam de parâmetros, critérios e indicadores de qualidade para esta oferta, amplamente distribuídos às escolas infantis e que agora precisam ser estudados no âmbito das instituições que passam a oferecer a educação infantil, apoiando a revisão de seus documentos referenciais.

A literatura da área, especialmente nas últimas três décadas, acumula subsídios suficientes para a orientação das práticas cotidianas na educação infantil, colocando a criança pequena na agenda social como um sujeito ativo, potente e que produz cultura, sendo papel das instituições o desenvolvimento de um currículo próprio que as considere como centro do processo curricular (BRASIL, MEC, 2009d), tanto em termos de suas necessidades como, também, no que tange às suas potencialidades (OLIVEIRA, 2014; BARBOSA, 2014).

A partir do ano de 2006, em função da Lei N $\mathrm{N}^{\circ}$. 11.274/06, que determinou a ampliação do ensino fundamental para nove anos de duração com ingresso das crianças aos seis anos de idade, o ponto de corte que deve ser observado para a matrícula inclui as crianças que completarem seis anos até o dia 31 de março do ano da entrada no ensino fundamental, permanecendo as demais no último ano da pré-escola, conforme normativas do Conselho Nacional de Educação (BRASIL, Resolução CEB/CNE No 01/2010 e Resolução $N^{\circ}$ 06/2010). Existem estudos da área da educação inicial que avaliam se essa ampliação, de fato, efetivou o direito a mais educação e mais tempo para as diferentes oportunidades de aprendizagens adequadas para as crianças pequenas, como propunham as orientações em documento orientador para esta implantação (BRASIL, MEC, 2009e). 
Passados 10 anos, cabe ainda questionar se tal mudança foi devidamente preparada em termos de organização das redes e escolas, acolhida às crianças e suas famílias, formação de profissionais, adequação das propostas pedagógicas e curriculares, regimentos escolares e espaços físicos. Ao contrário do previsto, restou em muitos casos, a perda do direito à infância para as crianças de seis anos (BARBOSA E CRAIDY, 2012; BARBOSA E DELGADO, 2012). Contextualizando as necessidades das crianças nestes processos de transição, Barbosa (2009) faz um alerta, mas também antevê possibilidades que poderiam ser abertas, a partir de um maior diálogo entre essas duas etapas:

\begin{abstract}
A ampliação da obrigatoriedade da frequência deve, necessariamente, estar vinculada à construção de uma concepção de anos iniciais do ensino fundamental que garanta a aprendizagem. A nova legislação pode, e deve ser encarada como uma oportunidade para discutir, refletir, implementar outros modos de educar as crianças do ensino fundamental, tendo em vista o respeito às crianças para que elas possam construir um processo educacional de sucesso. Entrar com seis anos na escola, aprender a gramática desta instituição, compreender seu modo de funcionamento não é tarefa rápida e fácil para uma criança. (BARBOSA, 2009, p. 6).
\end{abstract}

Considerando as dificuldades até hoje vivenciadas para a efetivação do "novo ensino fundamental" e o cenário descrito anteriormente em relação à chegada massiva de crianças de quatro e cinco anos em escolas que até então não ofereciam educação infantil, colocamos as duas situações em relação, no presente texto, articulando-as a partir de pressupostos do direito à educação de qualidade para crianças entre quatro e seis anos, abarcando esses três anos de escolaridade desde uma perspectiva de continuum educacional. Entendemos que, neste momento, os processos de acolhimento às crianças de quatro e cinco anos no ambiente escolar devem se constituir como prioridades para os sistemas municipais de ensino envolvidos, visando evitar contextos negativos de escolarização precoce em moldes tradicionais e conteudistas, como àqueles que atingiram as crianças de seis anos a partir de 2006 (BARBOSA E DELGADO, 2012).

Para além desse importante alerta acima apresentado, mas aproveitando esta situação trazida pela obrigatoriedade de matrícula escolar na pré-escola, defendemos um movimento produtivo das redes educacionais na direção de uma maior articulação entre as duas primeiras etapas da educação básica, pois, tanto no caso das crianças que ingressam na pré-escola quanto naquele das que iniciam o ensino fundamental, é o direito das crianças a bem viver seus tempos de infância que está em jogo (FLORES, 2015).

De maneira a desenvolver nossa argumentação, partimos de alguns elementos relevantes à organização da oferta educacional para as crianças entre quatro e seis anos, abarcando o caso das turmas de pré-escola e dialogando com as necessidades das crianças matriculadas no $1^{\circ}$ ano do ensino fundamental. Desta forma, a partir de dois tópicos interdependentes, o texto apresentará elementos referentes à: (1) organização e implementação da proposta político-pedagógica e (2) organização dos tempos e infraestrutura dos espaços, evidenciando quais são os compromissos dos sistemas de ensino para com uma oferta educacional de qualidade direcionada à faixa etária em questão.

\title{
Organização e implementação da proposta político-pedagógica
}


Iniciamos este capítulo destacando a importância do planejamento dos processos de acolhimento das crianças, de suas famílias, dos/das docentes e demais profissionais nos diferentes momentos de transição vividos nas instituições escolares. Quando nos referimos aos diversos processos de transição, pensamos tanto no caso das crianças vindas direto do ambiente familiar, sem terem frequentado a creche, quanto naquelas que se despedem de uma escola de educação infantil para seguir sua jornada educacional. Ainda, no caso das crianças que vivenciaram a pré-escola, a transição pode ocorrer na própria escola, quando esta também oferece o ensino fundamental; caso contrário, precisará ocorrer uma mudança de escola, de bairro e até de rede de ensino, para dar prosseguimento à trajetória escolar em outra instituição.

As formas com que cada escola organiza esses momentos são diversas e os sujeitos que demandam atenção nos momentos de transição se multiplicam, se reconhecermos ser importante acolher também aos novos professores e professoras que chegam às escolas, bem como aqueles/as que irão se despedir de uma turma e assumir um novo agrupamento de crianças. Temos ainda que considerar outros/as profissionais que fazem parte da comunidade escolar: merendeiras e merendeiros, auxiliares de serviços gerais, secretárias e secretários, guardas, entre outros/as. Em qualquer desses casos, estamos falando de coletivos diversos que se constituem em uma instituição educacional e se encontrarão envolvidos, de alguma forma, nessas dinâmicas de transição.

No caso da chegada à pré-escola, especialmente no contexto atual de obrigatoriedade, trata-se de um momento de expectativas para as crianças e para suas famílias que precisam ser acolhidas, orientadas e incluídas nos processos e instâncias de gestão da instituição. Para realizar esta inclusão, a escola precisa promover o estabelecimento de parcerias, reconhecendo as especificidades das crianças pequenas e aproveitando a presença cotidiana dos familiares, que costuma ser mais frequente quanto menor a criança. Valorizar esta presença é fundamental para que a mesma se mantenha ao longo do processo de escolarização, fortalecendo vínculos colaborativos na gestão da escola e garantindo o necessário acompanhamento aos processos de aprendizagem das crianças. Isto é, uma cultura de participação na vida escolar se constrói no dia a dia com o acolhimento a cada família na sua diversidade. A própria Ldben determina que a instituição deva "[...] articular-se com as famílias e a comunidade, criando processos de integração da sociedade com a escola." (BRASIL, LDBEN, Art. 12, inciso VI). Neste sentido, Albuquerque (2010) contribui apontando algumas iniciativas que podem materializar este acolhimento e estreitar esta integração:

As relações entre família e escola estão submetidas a um projeto escolhido e elaborado por ambos. Estar aberto preconiza que os portões precisam estar abertos à comunidade, os horários de atendimento precisam ser flexíveis e de acordo com as necessidades das famílias, os projetos também precisam ser construídos juntos, as famílias podem estar incluídas na gestão da escola, a escola precisa estar agregada ao contexto da comunidade. (ALBUQUERQUE, 2010, p.14)

Para acolher as crianças e as famílias, as equipes profissionais assumem papel de destaque, pois ao mesmo tempo em que também precisam ser acolhidas, são protagonistas nas ações voltadas aos demais. Por isso, é muito importante a colocação de profissionais com habilitação específica, condições e desejo para atuar na educação infantil e no primeiro ano do ensino fundamental. Respeitar as professoras, 
professores e demais integrantes das equipes nos seus desejos de atuar com as crianças ainda pequenas faz parte de uma postura de gestão que colabora para a realização das condições de desenvolvimento de um currículo a partir de práticas cotidianas (BRASIL, MEC 2009d). Afirmamos isto porque para acolher às crianças na perspectiva apontada tanto na teoria quanto nos documentos orientadores que embasam este artigo, é preciso aceitar a dimensão do cuidado como elemento inerente à prática educativa junto às crianças pequenas, o que demanda que as equipes profissionais tenham condições para fazer uma gestão sensível dos processos pedagógicos nestes inícios tão importantes da vida humana.

Colocamos, assim, os momentos de acolhimento e de transição entre etapas como elemento fundamental a ser explicitado a partir da revisão dos documentos de referência das escolas que passam a oferecer educação infantil, destacando as ações que serão realizadas para este fim e as articulações que se tornam necessárias nas redes próprias de ensino e, se for o caso, junto a outras de onde as crianças se originam. Staccioli (2013) nos ajuda a compreender a importância desses momentos e destaca que esse processo é permanente em uma instituição educacional:

Acolher uma criança na pré-escola significa muito mais que deixá-la entrar no ambiente físico da escola, designar-lhe uma turma e encontrar um lugar para ela ficar. O acolhimento não diz respeito apenas aos primeiros momentos da manhã ou aos primeiros dias do ano escolar. O acolhimento é um método de trabalho complexo, um modo de ser do adulto, uma ideia chave no processo educativo. (STACCIOLI, 2013, p.25).

Nessa perspectiva, efetivar estes processos de acolhimento a partir das DCNEI e das Diretrizes Curriculares Nacionais para o Ensino Fundamental - DCNEF, definidas na Resolução CEB/CNE N ${ }^{\circ}$ 7/2010 (BRASIL, MEC, 2010d), traz à equipe de gestão o desafio de elaborar um projeto de acolhimento permanente na escola que inclua toda a comunidade escolar: crianças e suas famílias, professoras e professores, entendo que a formação humana de todos/as os/as profissionais se dá ao longo da vida.

Em relação à habilitação para o exercício da docência junto à faixa etária que aqui estamos tematizando, a Ldben aponta a mesma exigência para atuar na educação infantil e nos anos iniciais do ensino fundamental, o curso superior de licenciatura plena, admitida, como formação mínima aquela em nível médio, na modalidade normal. Reafirmamos a necessidade de que profissionais que atuam na educação infantil, desde os grupos de bebês, sejam do magistério, mesmo sabendo que, neste momento de consolidação da educação infantil, ainda encontramos diferentes arranjos, tanto nas redes públicas quanto privadas, que contemplam equipes de apoio com profissionais contratados de várias formas e com diferentes atribuições. Vemos tais arranjos como situações problemáticas na medida em que, essas diferentes funções, nomenclaturas e condições de trabalho para diferentes cargos, em certos casos, ainda reforçam uma equivocada dicotomia entre o educar e o cuidar, repercutindo na qualidade da oferta educacional (PAULINO E CÔCO, 2016).

Assim, destacamos os documentos legais que afirmam a identidade do/a profissional que atua na educação infantil como sendo a de um professor/a, como é o caso das DCNEI e do Plano Nacional de Educação 2014-2024 (BRASIL, Lei No 13.005/14), que determina em sua Meta 8 que a formação em nível superior para todos/as profissionais da educação infantil deve ser garantida progressivamente. Como 
afirmam Pinto e Flores (2016) "[...] o direito à educação de qualidade para as crianças pequenas passa pela qualificação profissional dos docentes [...].” (PINTO E FLORES, 2016, p. 245-246). E esse processo de reconhecimento do profissional pressupõe, ainda, a criação de planos de carreira, remuneração digna e valorização docente, condições consagradas na literatura e indispensáveis a uma educação de qualidade (PAULINO E CÔCO, 2016).

Acreditamos que a formação inicial é importante, mas não é tudo e nem suficiente; os processos de formação continuada servem tanto para complementar a formação inicial quanto para a necessária atualização do trabalho docente, servindo para agregar novos saberes e experiências que possibilitem ressignificar as trajetórias formativas iniciais a partir de situações coletivas de planejamento, para atender às demandas de cada instituição, etapa, grupo. No caso aqui em questão, vemos como fundamental a abertura de um espaço de diálogo entre docentes das duas etapas, onde o currículo ofertado às crianças, no sentido amplo do termo, seja tema e onde seja possível identificar as especificidades de cada grupo etário, mas se evidencie, também, aquilo que os une. Nessa abordagem, docentes do $1^{\circ}$ ano do ensino fundamental, precisam planejar tanto junto com a pré-escola, quanto com o restante do grupo do $1^{\circ}$ ciclo, pois é nesse lugar/ano em que se situam a necessidade e a possibilidade de construção de uma ponte que permita às crianças uma travessia bem sucedida entre etapas. É importante destacar que essa postura de diálogo precisa ocorrer, também, entre as equipes pedagógicas destas duas etapas nas próprias secretarias de educação, a partir daí, repercutindo na garantia dos espaços formativos em cada unidade escolar.

Pensando na formação inicial de docentes, Radetski, Soldi e Silva (2000) afirmam a necessidade de que os cursos de formação tenham disciplinas que abordem a especificidade do trabalho com crianças de zero a seis, o que significa em nosso entendimento, contemplar as múltiplas linguagens como experiências a serem vivenciadas, também, pelos adultos em formação. Em certos casos, é a formação continuada que precisará dar conta de um trabalho com a dimensão lúdica do/a professor/a, pois em cada coletivo se reúnem pessoas com diferentes experiências em relação à formação inicial. Sendo assim, é no espaço de cada instituição, na maior parte das vezes, que precisarão ser criadas condições para experimentações das diferentes linguagens que precisamos garantir nas práticas cotidianas com as crianças entre quatro e seis anos, envolvendo música, artes plásticas e gráficas, cinema, fotografia, dança, teatro, poesia e literatura, como determinam as atuais DCNEI (BRASIL, Resolução CNE/CEB Nº 5, Art. IX). Sabemos que, para alguns/algumas docentes, habituados ao trabalho a partir de processos de alfabetização sistemáticos, a proposta de participação em brincadeiras e jogos poderá gerar estranhamento. Porém, concordamos com Piva (2016) sobre essa necessidade, que logo se tornará um prazer, pois: “O segredo, talvez, seja o de abrir espaços formativos para estranhamentos das práticas consolidadas e inauguração de novas possibilidades [...].” (PIVA, 2016, p. 47).

Para que esse processo aconteça, entendemos que cabe às mantenedoras e às equipes gestoras das escolas efetivarem uma política de formação continuada pautando tanto as especificidades da educação infantil quanto a articulação entre esta e o ensino fundamental, garantindo o diálogo entre as etapas, como determina o Artigo 10 da Resolução CNE/CEB, No 5/2009 (BRASIL, CNE/CEB, 2009a). E para que 
isto aconteça, é necessário que o compromisso destas instâncias para com estes diferentes espaços formativos esteja registrada nos próprios documentos referenciais da rede de ensino e das escolas, explicitando a demanda e garantindo os espaços e tempos necessários a esses encontros.

Sendo assim, para materializar a implementação de novas turmas de pré-escola nas escolas que antes atendiam exclusivamente ao ensino fundamental, é necessário um movimento concreto de adequação da Proposta Pedagógica e do Regimento Escolar, de maneira que não seja "uma escola dentro de outra escola", mas que as etapas tenham suas especificidades de acordo com o que é estabelecido nas normativas de cada uma, atendendo às necessidades e potencialidades das crianças em seus diferentes momentos de vida. Nesse processo de revisão documental, cabe destacar a normativa que aponta para:

[...] a necessidade de assegurar aos alunos um percurso contínuo de aprendizagens e torna imperativa a articulação de todas as etapas da educação, especialmente do ensino fundamental com a educação infantil, dos anos iniciais e dos anos finais no interior do Ensino Fundamental, bem como do Ensino Fundamental com o Ensino Médio, garantindo a qualidade da Educação Básica. (BRASIL, Parecer CNE/CEB No11/2010d, p.9).

Em nosso entendimento, as mantenedoras das redes de ensino e os conselhos de educação tem um papel fundamental na orientação às instituições escolares para efetivarem as revisões em seus documentos referenciais de maneira a contemplar a orientação curricular prevista nas diretrizes de cada etapa, demarcando a especificidade da educação infantil que não consiste em ser um momento preparatório para o ensino fundamental, ao mesmo tempo em que precisam ser evidenciadas e planejadas as possibilidades de construção de pontes, pois é sabido que "A falta de articulação entre as diferentes etapas da Educação Básica tem criado barreiras que dificultam o percurso escolar dos alunos". (BRASIL, CNE/CEB, Parecer No 11, 2010d, Art. 29).

A respeito da necessidade de reformular os documentos referenciais de uma escola e considerando que o currículo da educação infantil e o do primeiro ciclo do ensino fundamental devem respeitar as características das respectivas faixas etárias, é importante destacar que teremos crianças de seis anos frequentando tanto uma quanto outra etapa. Neste sentido, precisa ser explicitado nestes documentos, uma consideração especial para este grupo etário, isto é, o fato de uma criança ter completado seis anos a partir de primeiro de abril do ano em que ingressa no ensino fundamental não autoriza a escola a lhe impor práticas sistemáticas de alfabetização quatro horas por dia, pois, do ponto de vista do seu processo de desenvolvimento, ela também precisa de práticas pedagógicas apoiadas nas interações e na brincadeira como apontam as atuais DCNEI. Entendemos como fundamental defender este respeito aos direitos das crianças de seis anos, pois esse reconhecimento poderá, ainda, promover uma oxigenação no currículo de todo o primeiro ciclo do ensino fundamental como aponta o Parecer do Conselho Nacional de Educação que fixa diretrizes para o ensino fundamental de nove anos de duração (BRASIL, CNE/CEB, 2010d):

Na perspectiva da continuidade do processo educativo proporcionada pelo alargamento da Educação Básica, o Ensino Fundamental terá muito a ganhar se absorver da Educação Infantil a necessidade de recuperar o caráter lúdico da aprendizagem, particularmente entre as crianças de 6 (seis) a 10 (dez) anos que frequentam as suas 
classes, tornando as aulas menos repetitivas, mais prazerosas e desafiadoras e levando à participação ativa dos alunos. A escola deve adotar formas de trabalho que proporcionem maior mobilidade às crianças na sala de aula, explorar com elas mais intensamente as diversas linguagens artísticas, a começar pela literatura, utilizar mais materiais que proporcionem aos alunos oportunidade de raciocinar manuseando-os, explorando as suas características e propriedades, ao mesmo tempo em que passa a sistematizar mais os conhecimentos escolares. (BRASIL, CNE/CEB, Parecer $\mathrm{N}^{\circ} 11$, 2010d, p.21)

Contribuindo para esta perspectiva, Barbosa e Craidy (2012) recomendam um currículo centrando nas práticas cotidianas (BRASIL, MEC, 2009d) e não em expectativas de desempenho das crianças a partir de objetivos pré-definidos por etapas, idade ou anos de escolaridade, pois, planejando a partir destas práticas, estaríamos de fato colocando as crianças no centro do processo curricular. A partir dessa concepção, acreditamos que a educação infantil poderia inspirar práticas mais lúdicas e sensíveis também na oferta dos primeiros anos do ensino fundamental, desde que as escolas abrissem espaços formativos para esse diálogo, envolvendo crianças, famílias e profissionais, conforme destacam Flores e Silva (2015):

Propomos, enfim, o estabelecimento de pontes entre a educação infantil e o ensino fundamental que garantam a primeira etapa da educação básica o direito ao brincar livremente, sem a transformação da brincadeira em ensino, e a segunda, o caráter lúdico das aprendizagens necessárias a uma vida em sociedade plena de possibilidades e de motivações para que se busquem respostas aos desafios do cotidiano. (FLORES E SILVA, 2015, p.193).

Outra especificidade assegurada em documentos normativos (BRASIL, 2009a, 2009b) e abordada na literatura (OLIVEIRA-FORMOSINHO, 2014; MORO E OLIVEIRA, 2015), se refere às formas de elaboração da avaliação das crianças entre quatro e seis anos. As DCNEI apontam que na educação infantil como um todo, a avaliação deve se dar mediante acompanhamento e registro do desenvolvimento, materializada a partir de variada documentação pedagógica, a partir de parceria entre a escola e a família, sem o objetivo de promoção, pois não existe pré-requisito para o acesso ao ensino fundamental, além da idade de seis anos completos até 31 de março do ano de ingresso (BRASIL, Ldben, Art. 31), bem como não existe previsão de reprovação no $1^{\circ}$ ano do $1^{\circ}$ Ciclo (BRASIL, CNE/CEB, Parecer No $11,2010 \mathrm{~d}$ ).

A avaliação das crianças e o acompanhamento de seus percursos educativos precisa, ainda, da parceria entre a escola e a família. Moro e Oliveira (2014) reforçam este como um momento importante de aproximar as famílias das questões pedagógicas, ampliando seu envolvimento com a escola e com os processos de aprendizagem e desenvolvimento das crianças. Uma vez que haja grupos de crianças em idade de quatro e cinco anos em uma escola que ofereça também o ensino fundamental, a equipe pedagógica pode promover um diálogo entre as etapas sobre concepções de avaliação visando promover um olhar contínuo sobre os processos vivenciados pelas crianças, pois em relação ao $1^{\circ}$ ano do ensino fundamental, também as normativas determinam a não reprovação da criança na passagem para o $2^{\circ}$ ano. Além dessa garantia, existe a indicação da não retenção na passagem do $2^{\circ}$ ano para o $3^{\circ}$ ano, com o argumento da proposição de um Ciclo de Alfabetização (BRASIL, CNE/CEB, Parecer No 7, 2010d, art. 30, III, Parág. $\left.1^{\circ}\right)$. 
Nesse sentido, a concepção de avaliação nos documentos legais e normativos apresenta um ponto em comum, sustentando a ideia de um continumm entre as primeiras etapas da educação básica que visa ao "[...] pleno desenvolvimento da pessoa, seu preparo para o exercício da cidadania e sua qualificação para o trabalho." (BRASIL, CF/88, art. 205).

Considerando-se a necessidade da revisão de documentos como PPP e Regimento Escolar das escolas que até então ofereciam apenas ensino fundamental, adequando-os à oferta de educação infantil nos vários aspectos aqui apontados, é relevante destacar o papel dos conselhos municipais de educação ou dos próprios conselhos estaduais, nos casos de municípios que não possuem sistema próprio de educação. É papel de um conselho de educação estar atento às demandas de sua realidade e emitir documentos que orientem a oferta educacional em seu âmbito de atuação, atendendo a normas nacionais indicativas de padrões de qualidade. Como a educação infantil no âmbito municipal, historicamente, na maior parte dos casos, se constituiu ou tem maior oferta em instituições próprias, entendemos que este é um momento oportuno para que os conselhos revejam suas normas, verificando se tais documentos dão conta dos novos arranjos que surgem para a expansão da oferta de pré-escola. Caso a nova realidade não esteja prevista ou orientada claramente, é recomendável uma revisão da norma, de maneira a orientar as mantenedoras e as escolas na revisão de seus documentos referenciais dando visibilidade às crianças da pré-escola nos aspectos que se fizerem necessários.

Nesta seção, procuramos fortalecer a importância de um planejamento adequado das experiências iniciais a serem vividas pelas crianças nas instituições educacionais, evidenciando as responsabilidades colocadas para as diferentes instâncias de um sistema educacional, destacando que a atualização dos documentos referenciais de uma escola tem importante papel organizador das práticas coletivas, sendo que, na perspectiva de uma gestão democrática, a comunidade escolar precisa ser envolvida neste processo (FLORES E SILVA, 2015). Destacamos, também, a importância dos movimentos voltados à formação continuada, para a promoção dos indispensáveis diálogos entre profissionais que atuam nas duas etapas iniciais da educação básica.

Nesse sentido, entendemos que, de fato, o que necessita ser implementado inicialmente, por mais que se trate de uma abordagem complexa, seria uma postura de acolhimento mútuo por parte das duas primeiras etapas da educação básica, desde as equipes pedagógicas das secretarias de educação, até as equipes gestoras e demais profissionais das escolas, passando pelas comissões próprias dos conselhos de educação, com o objetivo maior de estudar as especificidades do trabalho com estes diferentes grupos etários, de maneira a preservar o direito aos tempos da infância tanto para as crianças que estão na educação infantil quanto para aquelas que estão no primeiro ano do ensino fundamental. Na próxima seção, desenvolveremos outros dois aspectos fundamentais em relação à preparação das instituições para o trabalho com crianças de quatro a seis anos: a organização dos tempos e a infraestrutura dos espaços nos quais as mesmas serão atendidas. 


\section{Organização dos tempos e a infraestrutura dos espaços}

A partir de diversos estudos, a organização dos espaços e da infraestrutura destinados ao cuidar e educar crianças pequenas tem sido apontada como elemento garantidor da qualidade da oferta de Educação Infantil (ZABALZA, 1998; HORN E GOBBATO, 2015). Os conselhos de educação, no âmbito dos sistemas de ensino, normatizam as condições desta organização para o atendimento da oferta educacional nas unidades escolares que os integram. Na educação infantil, são elementos centrais na garantia da qualidade dos espaços e da infraestrutura, a adequação dos espaços internos com salas próprias e mobiliário para a educação infantil; banheiros exclusivos e adequados à faixa etária; a existência de espaços externos para contato com a natureza, com brinquedos e materiais estruturados e não estruturados. Considerando-se a expansão da oferta de pré-escola em escolas que ofertam ensino fundamental, destacamos a responsabilidade das mantenedoras em relação a essa adequação, que deve apoiar-se na atualização das normativas dos conselhos de educação, bem como ser por este órgão acompanhada, em razão da demanda emergente trazida pela chegada das crianças pequenas a espaços não planejados para recebê-las. Em alguns casos, serão necessárias adequações quanto à iluminação direta, tipo de piso, segurança com janelas que não coloquem em risco a integridade das crianças, entre outros. (FLORES E TIRIBA, 2016). Trata-se de garantir espaços seguros, saudáveis e, ao mesmo tempo, desafiadores que permitam experiências educativas significativas, constituindo-se, para além de espaços, em ambientes. (HORN E GOBBATO, 2015).

Outro aspecto importante a ser considerado na organização dos novos espaços diz respeito ao cuidado estético, priorizando registros e produções das crianças, colocando a centralidade na participação e protagonismo das mesmas, como um dos conceitos-chave. Nesse sentido, é recomendável evitar o compartilhamento de salas com crianças de anos mais avançados do ensino fundamental, pois podem dificultar a disponibilização de materiais ao alcance das crianças pequena. Ostetto (2011) chama a atenção para a importância da adequada exposição das produções das crianças, ao mesmo tempo em que destaca o cuidado com a fixação de materiais em demasia:

Cuidar da estética dos espaços educativos é, portanto, matéria de primeira grandeza e não simples decoração, dirigida pelo gosto de cada um. [...] Por outro lado, por que encher todas as paredes com uma "decoração" ou mesmo com as produções das crianças? $\mathrm{O}$ excesso de estímulo visual acaba escondendo o que pretende mostrar, causando o que chamamos de poluição visual. É preciso também permitir o "silêncio da parede vazia", como uma forma de convidar novos protagonistas a deixarem suas marcas, para que novos discursos possam ser vistos/ouvidos por meio de renovadas imagens. (OSTETTO, 2011, p.34- 35).

Uma sala de educação infantil deve reproduzir mais um espaço de vida do que um espaço de escola da forma tradicional como temos em nosso imaginário e que nos constituiu ao longo dos anos. Trata-se de um espaço dentro de uma escola, mas que precisa ser um lugar de brincadeiras, de interações, de experiências, de descobertas, de escutas e de trocas entre as culturas trazidas dos diferentes contextos familiares e a cultura escolar. Para que este cotidiano de vida coletiva aconteça com qualidade, 
as escolas que atualmente estão recebendo as turmas de pré-escola necessitam considerar as especificidades e necessidades da infância na organização dos seus tempos e espaços.

O modelo tradicional que organiza a escola a partir de horários rígidos para garantir as disciplinas escolares e a "disciplina escolar", sem a participação das crianças, precisa ser revisto, pois vai de encontro à concepção de que as crianças têm seus próprios desejos e são capazes de opinar e fazer escolhas, desconsiderando as próprias DCNEI. Segundo Barbosa (2009):

As vozes das crianças precisam ser escutadas no dia a dia, pois elas, no encontro com o grupo, formulam a construção das suas histórias grupais e pessoais. Assim são respeitadas no seu direito de participar, nos seus desejos, deixando de serem apenas alunos para serem vistas como crianças, sujeitos históricos e produtores de cultura. (BARBOSA, 2009. p. 105).

Reforçando a ideia de consulta às crianças em relação à organização das atividades, Hoyuelos (2015) exemplifica uma possibilidade de alteração de uma rotina escolar contemplando o protagonismo das crianças e rompendo com a proposta de organização escolar tradicional:

Quando, nas escolas decidimos mudar de atividade [...], olhando o relógio, o mais comum é começar a gritar: "Vamos, guardem o material", acompanhado de algumas palmas ou de alguma música ritual, escolhida como estímulo para este momento. Em uma pesquisa realizada na Reggio Emilia sobre as normas escolares, as crianças de cinco anos protestaram contundentemente por esta "violenta" forma que lhes fazia cortar bruscamente o que estavam fazendo. Depois de uma acalorada e democrática discussão (como costumam ser os embates educativos nas escolas reggianas), as crianças entenderam a necessidade organizativa (para não desordenarem em excesso os tempos escolares) de terminar uma atividade e de recolher os materiais. Somente pediram aos professores duas coisas. A primeira, que não gritassem e que se dirigissem a elas individualmente. A segunda, é que, ao lhes pedir para terminar, dessem, ao menos, três minutos para fazê-lo. Porque três minutos? Porque parece ser o tempo psicológico necessário para terminar algo com calma, com respeito para que a própria atividade adquira sua cadência subjetiva de aparente final e encerramento, embora seja parcial. (HOYUELOS, 2015, p. 50).

Reforçando esta ideia da necessidade da participação das crianças na organização cotidiana da escola e os modos como são organizados os tempos da instituição, Barbosa (2000) afirma que os vários momentos de transição no cotidiano dos espaços coletivos de educação infantil costumam ser "[...] pouco pensados pelos educadores, embora eles contemplem uma questão muito importante que é o de atribuir uma significação aos acontecimentos, isto é, retirar as atividades de um rol de ações fragmentadas para um continuum.'"[...] (BARBOSA, 2000, p. 167-168). Para a autora (2000), é fundamental que os educadores compreendam que as crianças podem precisar de mais tempo para a realização de algumas atividades, inclusive complementando no dia seguinte algo planejado para durar apenas um dia, o que supera a primazia do relógio a partir da qual se organiza a lógica da vida adulta nos tempos atuais.

Com certeza, não podemos dissociar totalmente a organização dos tempos pedagógicos aos de uma organização maior que se refere aos tempos administrativos da escola. Contudo, no caso da ação cotidiana com as crianças pequenas, precisamos ter em mente que as decisões administrativas podem ter forte repercussão nas oportunidades oferecidas às crianças para o desenvolvimento da autonomia e para as interações com os pares. Assim, no caso da necessária adequação em certos momentos da rotina das escolas de ensino fundamental para contemplar as especificidades das turmas de pré-escola, entendemos 
que se coloca o mesmo desafio existente para as instituições que oferecem exclusivamente creche e préescola: "O principal desafio das escolas de educação infantil é garantir e manter o compromisso com a infância na organização da vida cotidiana alicerçada na participação democrática e na sustentabilidade". (BRASIL, MEC, 2009, p. 89)

Considerando que uma cultura de sustentabilidade pode ser construída desde a educação infantil, cabe também destacar a importância dos espaços externos como elemento de qualidade na oferta educacional. Assim, entendemos que a garantia de uma vivência segura em áreas externas, dentro ou fora da escola, pode se constituir em uma estratégia pedagógica que permita interações entre as crianças da préescola e as do $1^{\circ}$ ano do primeiro ciclo do ensino fundamental, pois é direito da faixa etária de quatro a seis anos esse contato direto com elementos da natureza, como refere o Parecer CNE/CEB no 20/09:

As crianças precisam brincar em pátios, quintais, praças, bosques, jardins, praias, e viver experiências de semear, plantar e colher os frutos da terra, permitindo a construção de uma relação de identidade, reverência e respeito para com a natureza. Elas necessitam também ter acesso a espaços culturais diversificados: inserção em práticas culturais da comunidade, participação em apresentações musicais, teatrais, fotográficas e plásticas, visitas a bibliotecas, brinquedotecas, museus, monumentos, equipamentos públicos, parques, jardins. (BRASIL, CNE/CEB, Parecer No 20, 2009b, p.15).

Nessa perspectiva, defendemos a possibilidade de romper com o tradicional confinamento nas salas de aulas para esses grupos etários, oportunizando vivências em diferentes espaços da escola, da comunidade e da cidade. Tiriba (2010) defende a necessidade do desemparedamento das crianças, privilegiando atividades ao ar livre que também devem ser proporcionadas às crianças do ensino fundamental, especialmente as do $1^{\circ}$ ano do primeiro ciclo, considerando a faixa etária das mesmas, respeitando a natureza humana e os encontros que podem acontecer ao ar livre, desde uma concepção que entende as crianças como seres da natureza:

Articulando-se às filosofias de nossos povos originários com a concepção spinoziana de que as ideias são constituídas com base nas afecções geradas também nos encontros com todo o universo social e natural em que estamos inseridos, abrir-seiam os caminhos para uma pedagogia da vida, respeitadora e alimentadora da paixão que as crianças têm pela vida ao ar livre. Paixão que se revela quando se lançam livremente às poças d'água, à terra, à lama, quando brincam com o vento. (FLORES E TIRIBA, 2016 , p. 175)

Planejar encontros em que aconteça a mistura de idades favorece o cuidado de si e do outro, pois se configuram como situações de cooperação e participação que também acontecem em casa e que na escola também devem ser proporcionadas. Neste contexto da obrigatoriedade da pré-escola e de expansão acelerada da oferta de vagas, muitas crianças vêm de casa sem terem frequentado uma instituição educativa ou, ainda, são oriundas de escolas pequenas com atendimento exclusivo de educação infantil e iniciam a vida escolar em uma instituição maior. Para uma acolhida adequada nesses casos, evidenciamos a importância da observação atenta dos adultos visando à segurança das crianças pequenas em seus deslocamentos pela escola, incluindo as áreas internas e externas, bem como os momentos de alimentação, idas ao banheiro e diversos espaços externos da escola "grande", sendo que, neste novo lugar, elas serão as crianças menores: "Quando a professora cuida das crianças, no sentido de estar atenta a elas, numa 
postura de escuta e diálogo com seus movimentos, contribui para que aprendam a cuidar de si mesmas e do coletivo do qual participam.” (SOUZA; MORO; SCALABRIN, 2016. p. 76).

Nestas experiências, para além das salas de referência, pode ser necessária a colaboração de outros profissionais da escola, sendo esta uma especificidade do trabalho com as crianças pequenas, quando do deslocamento de um espaço ao outro, e onde crianças e adolescentes convivem num mesmo espaço, para a qual a equipe gestora, especialmente nas escolas consideradas de grande porte, precisa estar atenta. Em relação à dimensão espaço físico, trazemos a este texto o documento "Educação Infantil: subsídios para a construção de uma sistemática de avaliação" (BRASIL, MEC, 2012) que aborda os eixos principais da qualidade em relação à oferta. Este documento apresenta um mapeamento de parâmetros para avaliação da educação infantil, sistematizando vários documentos do MEC e destacando aspectos principais que precisam ser considerados, independente da instituição em que ocorra a oferta educacional.

É preciso uma avaliação ampla dos espaços a serem utilizados pelas crianças, tanto internos quanto externos, no sentido do atendimento à legislação, respeitando exigências de proteção da insolação, vedações, isolamento acústico e térmico. A organização espacial é relevante, devendo facilitar os deslocamentos das crianças; e o atendimento a parâmetros técnicos e ambientais na seleção de materiais é fundamental na garantia da segurança. Dentre tantos aspectos, o documento citado destaca, ainda, a importância da existência, localização, acessibilidade e adequação dos sanitários para uso das crianças pequenas, bem como condições de saneamento. Ainda que pareçam questões óbvias, sabemos que muitas escolas não possuem as condições citadas, tornando-se locais inadequados para a educação e cuidado das crianças pequenas, sendo papel dos conselhos de educação realizar a devida fiscalização e orientação para as adequações necessárias.

Priorizando a discussão sobre as condições de oferta de pré-escola, o presente texto também buscou promover reflexões sobre a necessidade um maior diálogo entre as equipes responsáveis pela oferta da educação infantil e do $1^{\circ}$ ano do $1^{\circ}$ ciclo do ensino fundamental. Um de nossos argumentos é o fato de que, com o ponto de corte em 31 de março para ingresso no primeiro ano, todos os anos teremos crianças de seis anos frequentando tanto a pré-escola como o ensino fundamental; logo, entendemos que este momento em que ambas as etapas se encontram em um mesmo espaço físico pode ser uma oportunidade para a superação de fragmentações de históricas na articulação entre estas duas etapas da educação básica.

A qualidade da oferta de pré-escola em instituições com turmas de ensino fundamental, seja em escolas municipais, estaduais ou em instituições privadas, implica em uma responsabilidade dos gestores para com a garantia do direito destas crianças à infância. Entendemos, ainda que um olhar sensível tornase necessário no planejamento das vivências oportunizadas às crianças de seis anos que poderão estar na educação infantil ou no primeiro ano do ensino fundamental, onde as oportunidades educacionais se tornam diferentes, principalmente, por uma demanda de organização escolar e não diretamente por uma necessidade própria de um ou de outro grupo de crianças. 
Esta realidade complexa traz às mantenedoras, gestores/as, coordenadores/as pedagógicos, legisladores e demais profissionais da educação o compromisso para com a promoção de uma proposta pedagógica articulada "[...] visando a uma construção integral e integrada do saber, sem querer antecipar na educação infantil aquilo que terá seu tempo próprio a seguir nos processos do devir humano [...]" (FLORES E SILVA, 2015, p. 194). Mas, também, sem privar as crianças que já se encontram no $1^{\circ}$ ano das vivências lúdicas nos espaços das salas de referência e de um maior tempo de contato junto à natureza. Defendemos isso com base nas DCNGEB (2010), documento que normatiza a oferta da educação básica como um todo, com relação ao direito da criança de viver.

Esta responsabilização no sentido de reinventar e construir essa escola passa por uma concepção de criança participativa, protagonista e que tem o direito de viver suas infâncias com segurança, respeito, dignidade, em espaços adequados para compartilhar e ampliar seu conhecimento, sua cultura através da interação e do brincar, próprios para estas etapas. (BRASIL, CNE/CEB, Resolução N 4, 2010b, p. 9).

Enfatizamos nesta seção a importância da organização dos tempos e da infraestrutura dos espaços como parâmetro de qualidade para a ampliação da oferta pré-escolar em instituições que não ofertam exclusivamente educação infantil, a luz das normativas vigentes e de alguns documentos orientadores do MEC, além de outras fontes bibliográficas que podem subsidiar o planejamento adequado para atender à faixa etária de quatro e seis anos dentro de padrões que respeitem os direitos destas crianças a bem viver os seus tempos de infância (FLORES, 2015). Apoiamos-nos para estas proposições nas próprias DCNGEB (BRASIL, MEC, 2010), que se referem ao alargamento da concepção de organização de espaço físico, ultrapassando os muros da escola e incluindo outras possibilidades do entorno da cidade, visando qualificar e ampliar as experiências das crianças. Sem dúvida, para que avancemos nessa direção, é necessário que coletivos como as equipes pedagógicas, tanto das secretarias de educação quanto das escolas, assim como integrantes dos conselhos de educação deem prioridade a esta situação, reconhecendo sua importância no contexto das demandas educacionais.

\section{Considerações finais}

Nosso objetivo principal neste texto foi dar visibilidade a um conjunto de questões implicadas no direito à educação infantil que se encontram fragilizadas no contexto atual da obrigatoriedade da matrícula da pré-escola, chamando a atenção para as necessidades das crianças pequenas, que precisam ser prioridade no planejamento das práticas cotidianas em uma instituição que busque a qualidade na educação da infância. A obrigatoriedade de matrícula escolar na pré-escola tem gerado diversas alterações na organização dos sistemas municipais de ensino. Dentre estas, a criação de turmas de pré-escola em escolas que até então ofertavam exclusivamente o ensino fundamental, sejam elas municipais ou da rede estadual. Uma vez que estas crianças que ingressam aos quatro ou cinco anos têm direito a uma vaga na pré-escola, uma das subetapas que compõem a educação infantil, resgatamos pressupostos legais, normativos e teóricos visando a apoiar ações de planejamento no âmbito dos sistemas de ensino e nas 
escolas, incluindo-se as necessárias iniciativas de atualização de norma dos conselhos estaduais ou municipais de educação.

Para tanto, enfatizamos aspectos referentes à organização e implementação da proposta pedagógica das instituições e à organização e infraestrutura dos espaços, considerando estas como dimensões essenciais à garantia da efetivação de um lugar próprio para as crianças de quatro e cinco anos que vem sendo recebidas em espaços originalmente preparados para a oferta de ensino fundamental. Desenvolvemos aspectos que, intrinsecamente articulados e adequadamente organizados, constituem-se em condições que propiciarão às crianças e a suas famílias sentimentos positivos em relação ao início da trajetória em uma instituição escolar ou, ainda, permitirão uma transição segura entre as subetapas creche e pré-escola, quando for este o caso. Nesse sentido, em nosso entendimento, ao tratar-se da qualidade de instituições que oferecem educação infantil, a situação não se restringe, apenas, a garantir mais vagas em algum espaço físico, sendo, sim, de fundamental importância para a consolidação do direito à educação, a qualidade a ela agregada.

Além das demandas específicas das turmas de pré-escola das quais devem se ocupar as equipes gestoras das redes de ensino e das escolas, buscamos evidenciar que este momento faz voltar ao debate a necessidade de uma maior articulação entre a educação infantil e o ensino fundamental, processo do qual se beneficiariam ambas as partes, a partir do planejamento de situações de convívio entre docentes e grupos de crianças, bem como de integração curricular. Para tanto, destacamos como indispensável um diálogo acolhedor entre profissionais das secretarias de educação, dos conselhos de educação e das escolas, tendo como tema as possibilidades de articulação entre estas duas etapas, prevista na legislação e nas normativas educacionais e fartamente recomendada nos documentos orientadores e na literatura. Com certeza, as crianças e as famílias, se consultadas, ainda poderiam contribuir muito com as necessárias reorganizações dos ambientes escolares, assumindo um maior protagonismo na gestão das instituições efetivando um planejamento participativo.

\section{Referências}

ALBUQUERQUE. Simone Santos de. Educação das. Crianças Pequenas: da lógica cultural familiar às políticas públicas. Educ. Real., Porto Alegre, v. 35, n. 3, p. 139-156, set./dez., 2010. Disponível em: $<$ http://www.ufrgs.br/edu_realidade> Acesso em 23 de Março de 2017.

BARBOSA, Maria Carmen Silveira. Por amor \& por força: rotinas na Educação Infantil. Tese (Doutorado em Educação). UNICAMP, Campinas, 2000.

BARBOSA, Maria Carmen Silveira. Culturas Infantis: contribuições e reflexões. Revista Diálogo Educacional, v.14, n.43, $2014 . \quad$ Disponível em: <http://www2.pucpr.br/reol/index.php/dialogo?dd99=pdf\&dd1=14717/> Acesso em 28 de Março de 2017. 
BARBOSA, Maria Carmem. Apresentação. In: RAPOPORT, Andrea et al. (Orgs.). A criança de seis anos no ensino fundamental. POA: Mediação, 2009.

BARBOSA, Maria Carmem; CRAIDY, Carmen. Ingresso obrigatório no ensino fundamental aos seis anos. In: BARBOSA; DELGADO (Orgs.). A infância no ensino fundamental de 9 anos. Porto Alegre: Penso, 2012.

BARBOSA, Maria Carmem; DELGADO, Ana Cristina Coll. Alfabetização e escolarização: outros modos de pensar a leitura e a escrita com crianças. In: BARBOSA; DELGADO (Orgs.). A infância no ensino fundamental de 9 anos. Porto Alegre: Penso, 2012.

BRASIL. Congresso Nacional. Constituição da República Federativa do Brasil. Texto constitucional promulgado em 5 de outubro de 1988, com as alterações adotadas pelas Emendas constitucionais $\mathrm{n}^{\circ}$ 1/1992 a 90/2015, pelo Decreto legislativo no 186/2008 e pelas Emendas Constitucionais de revisão no 1 a 6/1994. - 48ª ed. Câmara dos Deputados. Brasília: Edições Câmara, 2015.

Lei $\mathrm{n}^{\circ}$ 9.394, de 20 de dezembro de 1996. Estabelece as diretrizes e bases da educação nacional. Diário Oficial da União, Brasília, 23 de dezembro de 1996.

Lei 13.005/14, de 25 de junho de 2014. Aprova o Plano Nacional de Educação e dá outras providências. Diário Oficial da União, Brasília, 26 de junho de 2014.

Emenda Constitucional No 59, de 11 de novembro de 2009. Acrescenta $\int 3^{\circ}$ ao art. 76 do Ato das Disposições Constitucionais Transitórias para reduzir, anualmente, a partir do exercício de 2009, o percentual da Desvinculação das Receitas da União incidente sobre os recursos destinados à manutenção e desenvolvimento do ensino de que trata o art. 212 da Constituição Federal, dá nova redação aos incisos I e VII do art. 208, de forma a prever a obrigatoriedade do ensino de quatro a dezessete anos e ampliar a abrangência dos programas suplementares para todas as etapas da educação básica, e dá nova redação ao $\$ $4^{\circ}$ do art. 211 e ao $\ 3^{\circ}$ do art. 212 e ao caput do art. 214, com a inserção neste dispositivo de inciso VI.

Diário Oficial da União, Brasília, 12 de novembro de 2009.

. Lei no 11.274, 6 de fevereiro de 2006. Altera a redação dos artigos. 29, 30, 32 e 87 da Lei n. 9394, de 20 de dezembro de 1996, que estabelece as diretrizes e bases da educação nacional, dispondo sobre a duração de 9 (nove) anos para o ensino fundamental, com matrícula obrigatória a partir dos 6 (seis) anos de idade. Diário Oficial da União, Brasilia: 6 de Fevereiro de 2006.

BRASIL. Conselho Nacional de Educação. Câmara de Educação Básica. Resolução CNE/CEB no 5, de 17 de dezembro de 2009. Fixa as Diretrizes Curriculares Nacionais para a educação infantil. 2009a. Disponível em: < http://www.mprs.mp.br/media/areas/gapp/arquivos/resolucao_05_2009_cne.pdf...> Acesso em 28 de Abril de 2017. 
Parecer CNE/CEB no 20, de 11 de novembro de 2009. Revisão das Diretrizes Curriculares

para a Educação Infantil. 2009b. Disponível em:

$<$ http://portal.mec.gov.br/component/docman/?task=doc download\&gid=2097> Acesso em 28 de abril de 2017.

Resolução CNE/CEB n ${ }^{\mathbf{0}}$ 1, de 14 de janeiro de 2010. Define Diretrizes Operacionais para a implantação do Ensino Fundamental de 9 (nove) anos. 2010a. Disponível em: < http://portal.mec.gov.br/index.php?option $=$ com docman\&view $=$ download\&alias $=15541-$ rceb001-10pdf\&category slug=abril-2014-pdf\&Itemid=30192> Acesso em 25 de Junho de 2017.

Resolução CNE/CEB nº 4, de 13 de julho de 2010. Define Diretrizes Curriculares Nacionais Gerais para a Educação Básica. 2010b. Disponível em: <http:/portal.mec.gov.br/dmdocuments/rceb004 10.pdf> Acesso em 15 de agosto de 2017.

Resolução CNE/CEB nº 6, de 20 de outubro de 2010. Define Diretrizes Operacionais para a matrícula no Ensino Fundamental e na Educação Infantil. 2010c. Disponível em: < http:/ / portal.mec.gov.br/index.php?option=com_docman\&view=download\&alias=15249rceb00610\&Itemid=30192>Acesso em 15 de agosto de 2017 .

Parecer CNE/CEB no 11, de 7 de julho 2010. Diretrizes Curriculares Nacionais para o Ensino $\begin{array}{llllll}\text { Fundamental de } & 9 & \text { (nove) anos. 2010d. Disponível em: }\end{array}$ $<$ http:/portal.mec.gov.br/component/docman/?task=doc download\&gid=6324> Acesso em $25 \mathrm{de}$ Maio de 2017.

BRASIL. Ministério da Educação. Secretaria da Educação Básica. Indicadores da Qualidade na Educação Infantil. Brasília: MEC/SEB, 2009c. Disponível em: <http:/portal.mec.gov.br/dmdocuments/indic qualit educ infantil.pdf.> Acesso em 25 de Maio de 2017.

BRASIL. Ministério da Educação. Práticas cotidianas na educação infantil: bases para a reflexão sobre as orientações curriculares. Brasília, 2009d. Disponível em: http://portal.mec.gov.br/dmdocuments/relat seb praticas cotidianas.pdf Acesso em 23 de Março de 2017.

BRASIL. Ministério da Educação. Secretaria de Educação Básica. Ensino Fundamental de nove anos: passo a passo do processo de implantação. Brasilia, 2009e. Disponível em: $<$ http://portal.mec.gov.br/dmdocuments/passo a passo versao atual 16 setembro.pdf $>$ Acesso em: 23 de Maio de 2017.

Parâmetros básicos de infraestrutura para instituições de educação infantil. Brasília: $\mathrm{MEC} / \mathrm{SEB}$, 2006a. Disponível em: 
$<$ http:/portal.mec.gov.br/seb/arquivos/pdf/Educinf/eduinfparinfestencarte.pdf. > Acesso em 25 de Maio de 2017.

Parâmetros nacionais de qualidade para a educação infantil. Brasília: MEC/SEB, 2006b. Disponível em: <http:/portal.mec.gov.br/seb/arquivos/pdf/Educinf/paraqualvol2.pdf. .> Acesso em 25 de Maio de 2017.

Educação Infantil: subsídios para a construção de uma sistemática de Avaliação. 2012.

Disponível

em:

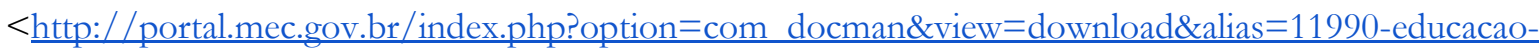
infantil-sitematica-avaliacao-pdf\&category slug=novembro-2012-pdf\&Itemid=30192> Acesso em 02 de Julho de 2017.

Contribuições para a Política Nacional: a avaliação em educação infantil a partir da avaliação de contexto. Curitiba: Imprensa/UFPR; Brasília: MEC/SEB/COEDI, 2015.

FLORES, Maria Luiza Rodrigues. Direito à Creche e à Pré-escola na Vigência do Plano Nacional de Educação - Lei Federal Nº 13.005/2014. Criança e Adolescente - Revista Digital Multidisciplinar do Ministério Público do Rio Grande do Sul. v. 1, n. 10, 2015.

Disponível

em:

https://www.ufrgs.br/einaroda/wpcontent/uploads/2016/11/direitoacrecheeapreescola.pdf Acesso em: 02 de Julho de 2017.

FLORES, Maria Luiza Rodrigues; SILVA, Maria Beatriz Gomes da. Articulações e tensões entre a educação infantil e o ensino fundamental: análises a partir do contexto recente das políticas educacionais brasileiras. In: FLORES, Maria Luiza Rodrigues; ALBUQUERQUE, Simone Santos de (Orgs.). Implementação do Proinfância no Rio Grande do Sul: perspectivas políticas e pedagógicas. Porto Alegre: Edipucrs, 2015.

FLORES, Maria Luiza R.; TIRIBA, Léa. A educação infantil no contexto da Base Nacional Comum Curricular: em defesa das crianças como seres da natureza, herdeiras das tradições culturais brasileiras. Debates em Educação, Maceió, v. 8, n. 16, p. 157-183, 2016. Disponível em:

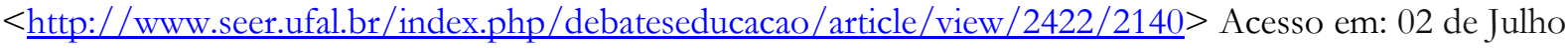
de 2017.

HORN, Maria da Graça Souza; Gobbato, Carolina. Percorrendo trajetos e vivendo diferentes espaços com crianças. In: FLORES, Maria Luiza Rodrigues; ALBUQUERQUE, Simone Santos de (Orgs.). Implementação do Proinfância no Rio Grande do Sul: perspectivas políticas e pedagógicas. Porto Alegre: Edipucrs, 2015. 
HOYUELOS, Alfredo. Os tempos da infância. In: FLORES, Maria Luiza Rodrigues; ALBUQUERQUE, Simone Santos de (Orgs.). Implementação do Proinfância no Rio Grande do Sul: perspectivas políticas e pedagógicas. Porto Alegre: Edipucrs, 2015.

MORO, Catarina; OLIVEIRA, Zilma Moraes Ramos de. Avaliação e educação infantil: crianças e serviços em foco. In: FLORES, Maria Luiza Rodrigues; ALBUQUERQUE, Simone Santos de (Orgs.). Implementação do Proinfância no Rio Grande do Sul: perspectivas políticas e pedagógicas. Porto Alegre: Edipucrs, 2015.

MOVIMENTO INTERFÓRUNS DE EDUCAÇÃO INFANTIL DO BRASIL. MIEIB. Educação Infantil e a Base Nacional Comum Curricular. Site institucional. Disponível em: http://www.mieib.org.br/educacao-infantil-e-base-nacional-comum-curricular-2/ Acesso em: 14 de agosto de 2017.

OLIVEIRA, Zilma Moraes Ramos de. Currículo na educação infantil: dos conceitos teóricos à prática pedagógica. In: SANTOS, Marlene; RIBEIRO, Maria Izabel Souza (Orgs.). Educação Infantil: os desafios estão postos e o que estamos fazendo? Salvador: Sooffset, 2014.

OLIVEIRA-FORMOSINHO, Júlia. O projeto EEL-DQP: avaliação e desenvolvimento da pedagogia sustentada na documentação pedagógica. In: GUIMARÃES, C. M.; CARDONA, M. J.; OLIVEIRA, D. (Orgs.). Fundamentos e práticas da avaliação na educação infantil. POA: Artmed, 2014.

OSTETTO, Luciana Esmeralda. Educação Infantil e Arte: sentidos e práticas possíveis, 2011. Disponível em: < http://www.acervodigital.unesp.br/handle/123456789/320> Acesso em 13 de Mar. de 2017.

PAULINO, V. B. R. ; COCO, Valdete. Políticas públicas educacionais: vozes que emergem no trabalho docente na Educação Infantil. Ensaio: aval.pol.públ.Educ. [online], Rio de Janeiro, v.24, n. 92, p. 697718, jul./set. 2016. Disponível em: < http://ref.scielo.org/yns5h4> Acesso em 20 de Julho de 2017.

PINTO, Adriana Flério Esteves; FLORES, Maria Luiza Rodrigues. Formação inicial e valorização das professoras na Educação Infantil. In: ALBUQUERQUE, Simone Santos de; FELIPE, Jane; CORSO, Luciana Vellinho (Org.). Para pensar a educação infantil em tempos de retrocessos: lutamos pela educação infantil. Porto Alegre: Evangraf, 2017.

PIVA. Luciane Frosi. Transições, rupturas e continuidades na educação infantil. (Trabalho de conclusão). Curso de Especialização em Coordenação Pedagógica. Porto Alegre, UFRGS, 2016.

RADETSKI, Cláudia Maria, SOLDI, Susana Fátima e SILVA, Verônica F. Alves da. Formação do profissional de Educação Infantil. Zero-a-Seis. v. 2, n. 3 (2000): jul./dez. 2000. P. 
SOUZA, Gizele de; MORO, Catarina; COUTINHO, Angela Scalabrin (Orgs.). Formação da Rede em Educação Infantil: avaliação de contexto. Curitiba: Appris, 2015.

STACCIOLI, Gianfranco. Diário do acolhimento na escola da infância. Campinas, SP: Autores Associados, 2013.

TIRIBA, L. Crianças da natureza. In: I Seminário Nacional: Currículo em Movimento - Perspectivas Atuais, 2010. ANAIS... Belo Horizonte: Universidade Federal de Minas Gerais, 2010. v. 1. p. 1-20.

ZABALZA, Miguel A. Qualidade em educação infantil. Porto Alegre: ArtMed, 1998. 